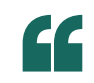

the description of physical

$d^{8} \mathrm{Cu}$ "' in any case is likely unjustified

g

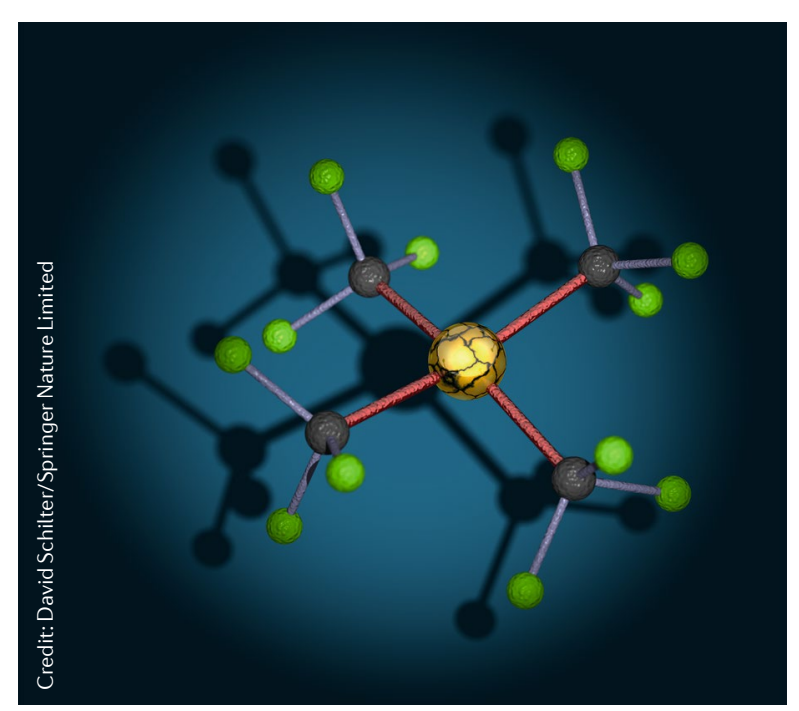

Copper has a central role in many biological and synthetic catalysts. Although copper complexes typically have formal oxidation states of $+\mathrm{I}$ and $+\mathrm{II}$, high-valent $\mathrm{Cu}^{\mathrm{III}}$ has been implicated in reactive intermediates. For example, the $\mathrm{Cu}^{\mathrm{II} / \mathrm{I}}$ redox pair is suggested to perform analogously to $\mathrm{Pd}^{\mathrm{I} / 0}$ in bond formation chemistries. Several complexes formally assigned as $\mathrm{Cu}^{\mathrm{III}}$ have been isolated, but peculiarities remain in understanding their electronic structures. For instance, $\left[\mathrm{Cu}\left(\mathrm{CF}_{3}\right)_{4}\right]^{-}$can formally be considered to have four $\mathrm{CF}_{3}^{-}$ligands surrounding a $\mathrm{Cu}^{\mathrm{III}}$ centre, yet the frontier orbitals have predominantly ligand character. This suggests that the monoanion may better be described as a $d^{10} \mathrm{Cu}^{1}$ complex. Such 'ligand field inversion' contrasts the typical assignment of ligand field molecular orbitals as being metal-centred. Oftentimes, $d^{9} \mathrm{Cu}^{\mathrm{II}}$ is distinguished from $d^{8} \mathrm{Cu}^{\mathrm{III}}$ by means

\section{Copper comeuppance} exceed the proposed $8,981 \pm 0.5 \mathrm{eV}$ range considered diagnostic of $\mathrm{Cu}^{\mathrm{II}}$ and some fall in the $8,979 \pm 0.5 \mathrm{eV}$ range normally ascribed to $\mathrm{Cu}^{\mathrm{II}}$ species, emphasizing the ambiguity in using the $\mathrm{Cu} \mathrm{K}$-edge energy to assign oxidation states. However, Lancaster and colleagues find that the $\mathrm{L}_{2,3}$-edges observed for the formally $\mathrm{Cu}^{\mathrm{III}}$ species, which arise from $2 p \rightarrow 3 d$ transitions, have intensities reflective of physically more reduced $\mathrm{Cu}$ centres. The team compared these data with robust covalency standards, thereby extracting the $d$-orbital contributions to the lowest unoccupied molecular orbital (LUMO) and singly occupied molecular orbital (SOMO) of each complex. Importantly, the LUMOs/SOMOs of all formally $\mathrm{Cu}^{\mathrm{II}}$ complexes have $<50 \% \mathrm{Cu} 3 d$ character, suggesting that these species each have an inverted ligand field and substantial covalent character. Experimental Cu $3 d$ contributions were very closely matched by values calculated using hybrid DFT. Given the strong correlation between the calculated and experimental results, modelling nine additional reported $\mathrm{Cu}$ complexes revealed all but one $\left(\left[\mathrm{CuF}_{6}\right]^{3-}\right)$ to have bonds with similarly covalent bonding (and its $\mathrm{Cu}-\mathrm{F}$ bonds, with $61 \%$ $\mathrm{Cu} 3 d$ character, would still be considered covalent).

Altogether, the XAS data and computational modelling emphasize an important distinction between formal and spectroscopic oxidation states. Indeed, careful examination of a range of $\mathrm{Cu}$ complexes by multi-edge XAS does not reveal any signature that is unambiguous evidence for the physical $\mathrm{Cu}^{\text {III }}$ oxidation state. Instead, the highly covalent bonding present in ' $\mathrm{Cu}$ III' complexes suggests substantial hole character to remain on the ligands. Importantly, Lancaster posits that "the description of physical $d^{8} \mathrm{Cu}^{\text {III }}$ in any case is likely unjustified, with the exception perhaps of $\left[\mathrm{CuF}_{6}\right]^{3-}$." This conclusion has implications for understanding ligand reactivity and reaction mechanisms. For instance, instead of undergoing redox, a metal may simply modulate the charge on its ligands, such that they are more non-innocent than we think.

Adam Weingarten, Senior Editor, Nature Communications

ORIGINAL ARTICLE DiMucci, I. M. et al. The myth of $d^{8}$ copper(III).J.Am. Chem. Soc. 141, 18508-18520 (2019) 